\title{
Effect of synergistic action of ultrasonic vibration and solidification pressure on tensile properties of vacuum counter-pressure casting aluminum alloy
}

\author{
*Qing-song Yan, Gang Lu, Gui-ming Luo, Bo-wen Xiong, Qiang-qiang Zheng \\ National Defense Key Discipline Laboratory of Light Alloy Processing Science and Technology, Nanchang Hangkong University, Nanchang \\ 330063, China
}

\begin{abstract}
The effect of synergistic action of ultrasonic vibration and solidification pressure on tensile properties of vacuum counter-pressure casting ZL114A alloys was studied systemically through testing and analyzing the tensile strength and elongation subjected to different ultrasonic powers and solidification pressures. The results indicate that the synergistic action of ultrasonic vibration and solidification pressure can result in the refinement of grains and improvement of tensile properties. Both the highest tensile strength and elongation of aluminum alloy were obtained under synergistic action of $600 \mathrm{~W}$ ultrasonic power and $350 \mathrm{kPa}$ solidification pressure. Moreover, the tensile fracture morphology shows obvious ductile fracture characteristics. When the solidification pressure is lower than $300 \mathrm{kPa}$, the effect of ultrasonic power on tensile strength and elongation is more obvious, but when the solidification pressure is higher than $300 \mathrm{kPa}$, the effect of solidification pressure on tensile strength and elongation is greater. Meanwhile, the size and morphology of the eutectic silicon were improved significantly by the ultrasonic vibration and pressurized solidification. The strip and massive eutectic silicon phase are completely converted into small short rod-like and evenly distributed Si phases at the grain boundary of primary $\alpha-A \mathrm{l}$.
\end{abstract}

Key words: ultrasonic power; solidification pressure; vacuum counter-pressure casting; aluminum alloy; tensile property

CLC numbers: TG146.21 Document code: A

Article ID: 1672-6421(2018)06-411-07

\begin{abstract}
A luminum alloy castings have gained broad applications for their high specific strength, simple production process and low cost in the automotive and aerospace industry ${ }^{[1-2]}$. However, it is difficult to consistently produce sound aluminum alloy castings by traditional casting methods because of the microporosity and coarse microstructures ${ }^{[3-4]}$ which degrade the mechanical properties of aluminum alloy castings. Therefore, many efforts have been made to refine the microstructure and increase the mechanical properties of aluminum alloy castings, such as solidification under the conditions of ultrasonic vibration and pressure.

In the 1930s, scholars began to study the effect of ultrasonic vibration on metal solidification, and considered that ultrasonic vibration could produce a cavitation effect, forming a lot of cavitation bubbles in the molten metal, which lead to internal evaporation of liquid and local temperature fluctuation, which are advantageous to the refinement of grains and improvement of mechanical
\end{abstract}

*Qing-song Yan

Male, Ph.D., Professor. Research interest: liquid precision forming technology.

E-mail: yanqs1973@126.com.

Received: 2018-04-08; Accepted: 2018-09-25 properties ${ }^{[5-8]}$. Eskin G. I. ${ }^{[9-10]}$ studied the solidification process of aluminum alloy using $10 \mathrm{~kW}$ ultrasonic waves, and the experimental results indicated that the tensile strength of aluminum alloy could be increased by $6 \%-10 \%$ after ultrasonic treatment. Tzanakis I. et al. ${ }^{[11-12]}$ systematically studied the ultrasonic treatment of molten aluminum, found the ultrasonic capillary effect, and considered that the ultrasonic cavitation intensity was mainly influenced by the distance from ultrasonic source, melt temperature and input power. Vacuum counter-pressure casting technology is a kind of advanced counter-gravity method subjected to the pressure field during the whole solidification process of the molten metal. Research ${ }^{[13-15]}$ indicates the pressure could promote the aluminum alloy molten metal flow toward the dendrite space through narrow passages among solidification dendrites. Because the secondary dendrite arm spacing of the aluminum alloy in the solidified area is normally 10-100 microns, the flow channel among solidification dendrites of molten metal is very narrow, and the flow behavior may be regarded as extrusion and infiltration effect. Moreover, the dendrites forming a continuous skeleton 
have certain strength during solidification, when the extrusion and infiltration force is greater than their strength, the dendrite will be plastically deformed, even crushed and broken by the molten metal flow, resulting in the refinement of the grain and the improvement of mechanical properties. These pioneering works offer an essential theory basis for the future research of the counter-pressure casting technique.

To give a further investigation on the effects of solidification process on the tensile properties of vacuum counter-pressure casting aluminum alloy, ultrasonic vibration was applied during the solidification process. Taking high strength ZL114A alloy used in aerospace industry as the research object, the present study focuses on the effects of synergistic action of ultrasonic power and solidification pressure on microstructure, tensile strength and elongation of vacuum counter-pressure casting ZL114A aluminum alloy.

\section{Experimental procedure}

The vacuum counter-pressure casting equipment with ultrasonic vibration is shown in Fig. 1, and the process of synergistic action of ultrasonic vibration and solidification pressure is shown in Fig. 2. When the vacuum stage is completed, ultrasonic vibration is applied at the stages of mould filling, pressure rising, and holding, until the pressure is released.

Aluminum alloy ZL114A was used. The alloy ingot with a diameter of $12 \mathrm{~mm}$ and a length of $100 \mathrm{~mm}$ was melted in a graphite crucible inside an electric resistance furnace. When the temperature of the furnace was raised to $700{ }^{\circ} \mathrm{C}$ and held for $20 \mathrm{~min}$, the molten metal was pressed through a feeding tube into a permanent mould cavity made of \#45 steel with a preheated temperature of $270{ }^{\circ} \mathrm{C}$ under a designed filling pressure difference of $35 \mathrm{kPa}$. The permanent mould cavity was controlled at a negative pressure of $20 \mathrm{kPa}$. Four different holding pressures $(200,250,300$ and $350 \mathrm{kPa}$ with the same holding time of $80 \mathrm{~s}$ ) and four different ultrasonic power values $(0,300,600$ and $900 \mathrm{~W})$ were used, as shown in Table 1.

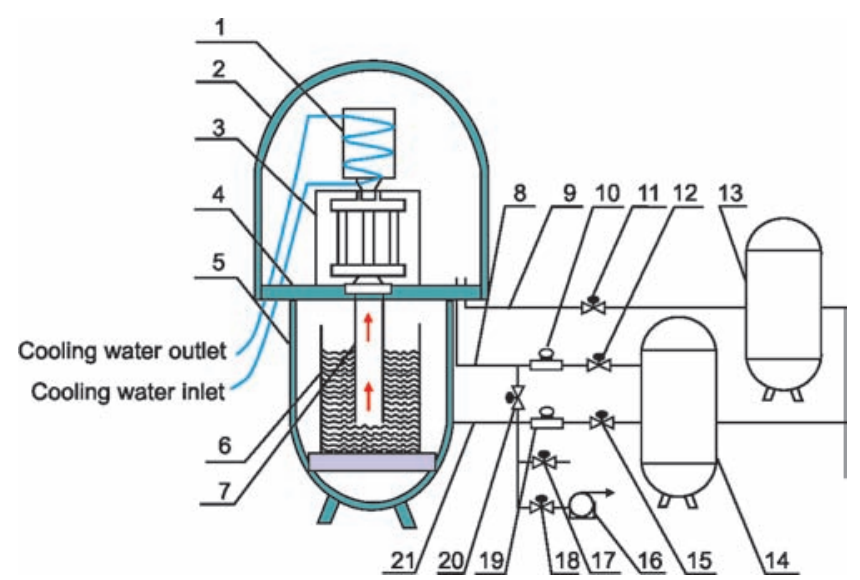

1-Ultrasonic device; 2-Upper kettle; 3-Mould; 4-Clapboard; 5-Lower kettle; 6-Crucible; 7-Rising tube; 8, 9, 21-Gas tube; $10,19-$ Regulating valve; $11,12,15,17,18,20$-Switch valve; 13, 14-Gas jar; 16-Vacuum pump

Fig. 1: Schematic of vacuum counter- pressure casting under ultrasonic vibrationd

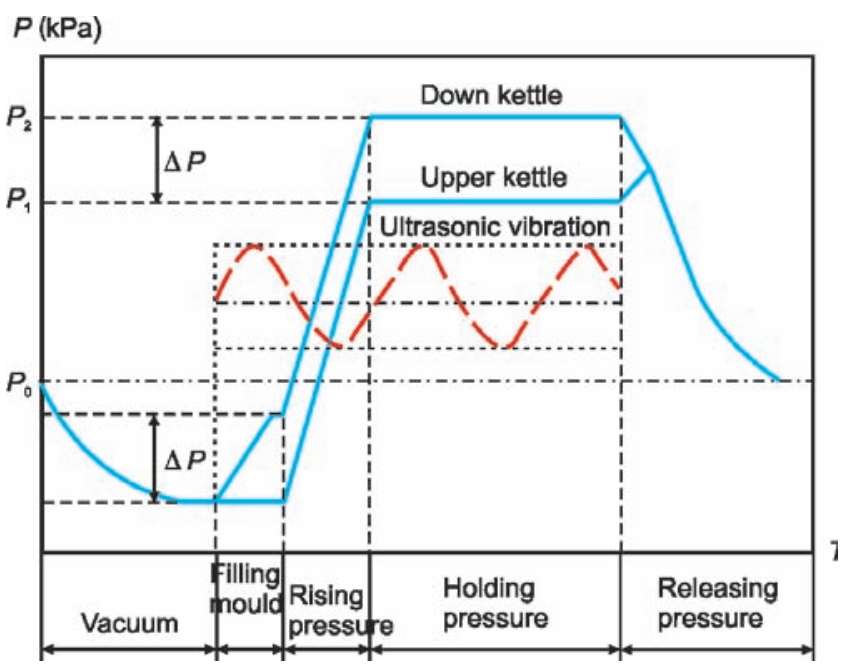

Fig. 2: Process of synergistic action of ultrasonic vibration and solidification pressure

Table 1: Technical parameters of ultrasonic power and solidification pressure

\begin{tabular}{|c|c|c|c|c|c|}
\hline Sample No. & $\begin{array}{l}\text { Vacuum degree } \\
(\mathrm{kPa})\end{array}$ & $\begin{array}{c}\text { Pressure } \\
\text { difference (kPa) }\end{array}$ & $\begin{array}{l}\text { Time of holding } \\
\text { Pressure (s) }\end{array}$ & $\begin{array}{l}\text { Solidification } \\
\text { pressure (kPa) }\end{array}$ & Ultrasonic power (W) \\
\hline 1 & & & & 200 & 0 \\
\hline 2 & & & & 200 & 300 \\
\hline 3 & & & & 200 & 600 \\
\hline 4 & & & & 200 & 900 \\
\hline 5 & & & & 250 & 0 \\
\hline 6 & & & & 250 & 300 \\
\hline 7 & & & & 250 & 600 \\
\hline 8 & & & & 250 & 900 \\
\hline 9 & 20 & 35 & 80 & 300 & 0 \\
\hline 10 & & & & 300 & 300 \\
\hline 11 & & & & 300 & 600 \\
\hline 12 & & & & 300 & 900 \\
\hline 13 & & & & 350 & 0 \\
\hline 14 & & & & 350 & 300 \\
\hline 15 & & & & 350 & 600 \\
\hline 16 & & & & 350 & 900 \\
\hline
\end{tabular}


The tensile strength and elongation at room temperature of the specimens were investigated. $\mathrm{T} 6$ heat treatment (heated to $535^{\circ} \mathrm{C}$ and held for $10 \mathrm{~h}+$ quenched in $80{ }^{\circ} \mathrm{C}$ warm water for $15 \mathrm{~s}+$ aged at $160{ }^{\circ} \mathrm{C}$ for $8 \mathrm{~h}+$ cooled to room temperature) was carried out. Then, the tensile test bars were machined according to the dimensions shown in Fig. 3. The tensile tests were performed using a WDW-50 testing machine.

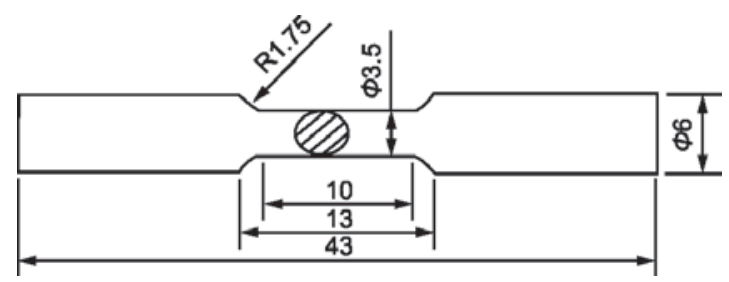

Fig. 3: Dimensions of tensile test bar $(\mathrm{mm})$

\section{Results and discussion}

\subsection{Effect of ultrasonic power on tensile properties}

The variation trends of the tensile strength and elongation of vacuum counter-pressure casting ZL114A aluminum alloy with the ultrasonic power under different solidification pressures are shown in Fig. 4. With the increase of ultrasonic power, the tensile strength (solid line) and elongation (dashed line) of the aluminum alloy firstly increase, and then gradually decrease when the ultrasonic power is greater than $600 \mathrm{~W}$.

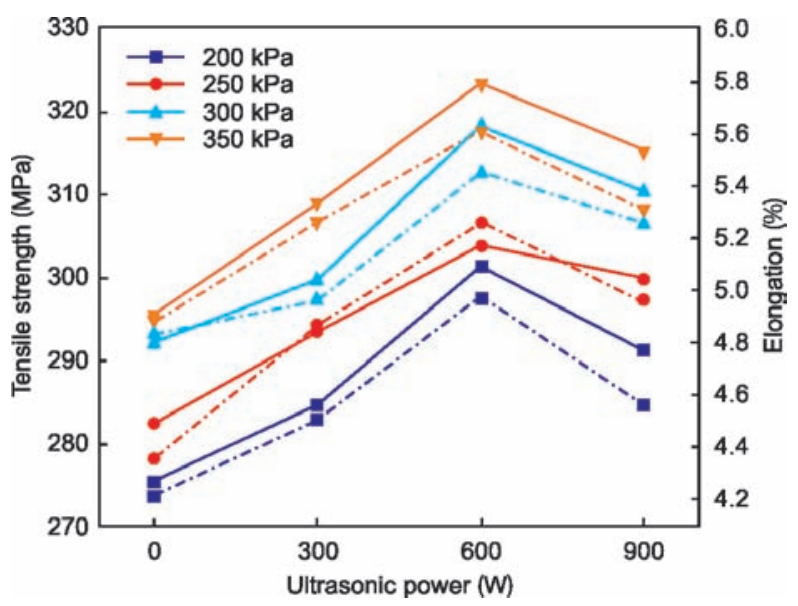

Fig. 4: Variation of tensile strength and elongation with ultrasonic power

Ultrasonic wave can produce much special ultrasonic effect, such as strong cavitation, thermal effect and attenuation effect in the molten alloy. With the increase of ultrasonic power, the effect of cavitation and acoustic flow effect is more and more strong, the grains of the aluminum alloy are refined ${ }^{[16]}$, and the tensile properties are improved. However, the greater the ultrasonic power, the more significant the thermal effect. When the ultrasonic power is greater than $600 \mathrm{~W}$, much ultrasonic energy is absorbed by the molten alloy, which easily causes a partial molten temperature increase, and therefore extends the growing time of the dendrites. So, the microstructure will become coarse ${ }^{[17]}$, and the tensile properties worsen.

\subsection{Effect of solidification pressure on tensile properties}

At the same ultrasonic power, changing trends of the tensile strength and elongation of the alloy with solidification pressure are shown in Fig. 5. With the increase of solidification pressure, the tensile strength (solid line) and elongation (dashed line) of the alloy increase gradually.

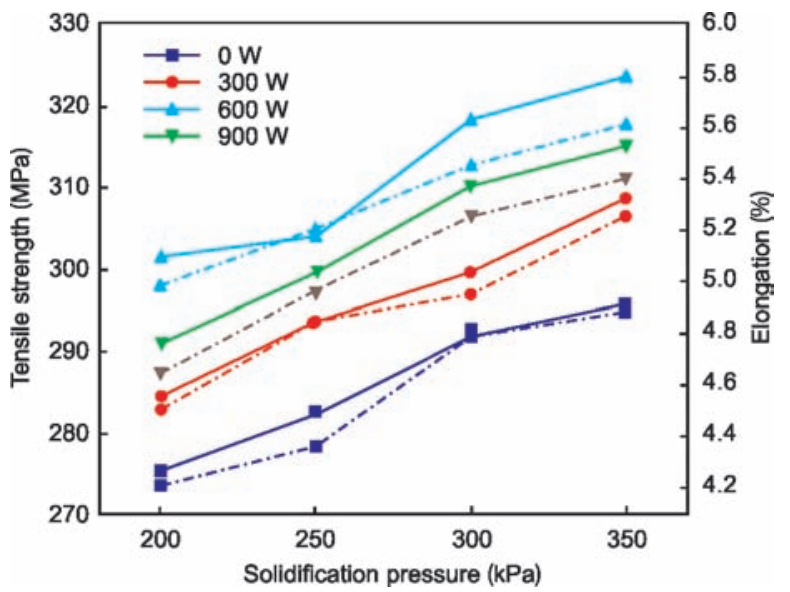

Fig. 5: Dependence of tensile strength and elongation on solidification pressure

During vacuum counter-pressure casting, the high pressure runs through the whole solidification process. Consequently, the vacuum counter-pressure casting process has a strong extrusion and infiltration effect. The extrusion and infiltration capacity of vacuum counter-pressure casting ZL114A aluminum alloy can be calculated by Eq. (1), as follows ${ }^{[18]}$ :

$$
\Delta G=\frac{K\left(P_{X}+\frac{2 \sigma}{r}-P_{s}-P_{g}\right)}{\mu \Delta L} F \cdot \Delta \tau
$$

where $\Delta G$ is the capacity of extrusion and infiltration in shrinkage cavity, $P_{X}$ is solidification pressure at $X$ location, $P_{s}$ is static pressure of molten metal, $P_{g}$ is pressure separating out gas among dendrites, $\sigma$ is surface tension of molten metal, $L$ is depth of extrusion and infiltration, $F$ is area of extrusion and infiltration, $\Delta t$ is time of extrusion and infiltration, and $k$ is infiltration ratio.

The extrusion and infiltration capacity of vacuum counterpressure casting ZL114A aluminum alloy is determined mainly by solidification pressure, as can be inferred from Eq. (1). With the increase of solidification pressure, the extrusion and infiltration capacity of the alloy becomes stronger, which is advantageous to improve the flow ability of aluminum alloy through narrow channels among solidified dendrites. Furthermore, even if aluminum alloy dendrites form a continuous skeleton during the extrusion and infiltration process, they will be crushed and broken by the molten metal flow when their strength is lower than the extrusion and infiltration pressure, resulting in the refinement of grains ${ }^{[19-20]}$. Accordingly, the tensile properties increase with the increase of holding pressure. 


\subsection{Effect of synergistic action of ultrasonic vibration and solidification pressure on tensile properties and microstructure of the alloy}

Under synergistic action of ultrasonic vibration and solidification pressure, tendency of the tensile strength and elongation of vacuum counter-pressure casting ZL114A aluminum alloy are shown in Fig. 6 and Fig. 7, respectively.

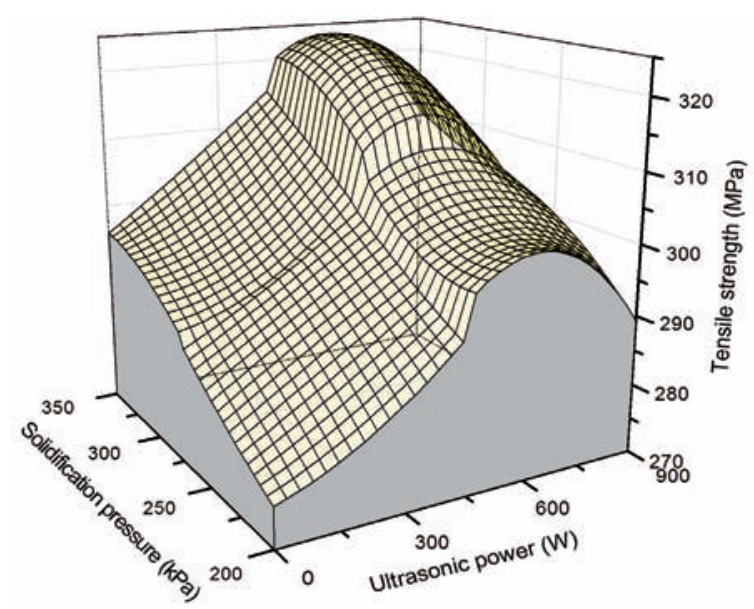

Fig. 6: Dependence of tensile strength on ultrasonic power and solidification pressure

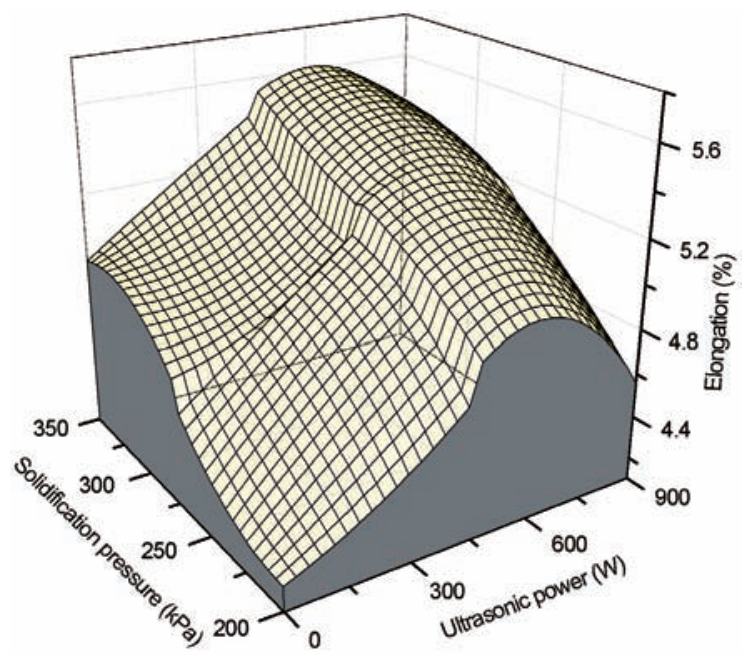

Fig. 7: Dependency of elongation on ultrasonic power and solidification pressure

It can be seen that both the ultrasonic vibration and solidification pressure have effects on tensile strength and elongation, and the tensile strength and elongation of aluminum alloy are the highest under the synergistic action of $600 \mathrm{~W}$ ultrasonic power and $350 \mathrm{kPa}$ solidification pressure. When the solidification pressure is less than $300 \mathrm{kPa}$, the effect of ultrasonic power on the tensile strength and elongation is more obvious, but when the solidification pressure is more than $300 \mathrm{kPa}$, the effect of solidification pressure on the tensile strength and elongation is greater.

The tensile fracture morphologies of ZL114A alloys are shown in Fig. 8. The tensile fracture morphology under $600 \mathrm{~W}$ ultrasonic vibrations without solidification pressure is mainly of tough dimples, and there are also some cleavage fracture and shrinkage defects, as shown in Fig. 8(a). The tensile fracture morphology under $350 \mathrm{kPa}$ solidification pressure without ultrasonic vibration is also mainly of tough dimples, and the size and depth of tough dimples increase, as shown in Fig. 8(b). The tensile fracture morphology under $600 \mathrm{~W}$ ultrasonic power and $350 \mathrm{kPa}$ solidification pressure shows obvious ductile fracture characteristics, and the size and depth of tough dimples increase significantly, and the tearing ridge appears, as shown in Fig. 8(c).

Further, the size and morphology of the eutectic silicon were optimized significantly by the ultrasonic power and solidification pressure as observed in the microstructures of ZL114A alloy,
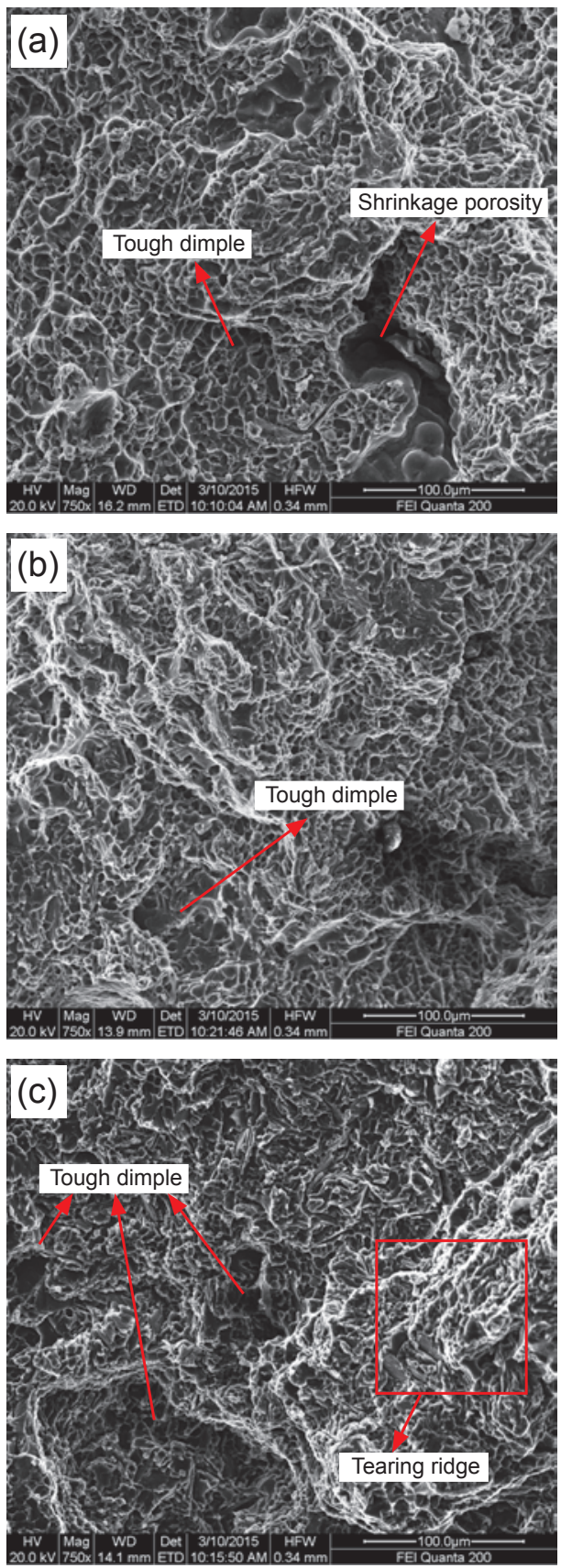

Fig. 8: Tensile fracture morphology of ZL114A alloys under different conditions: (a) $600 \mathrm{~W}$ ultrasonic power; (b) $350 \mathrm{kPa}$ solidification pressure; (c) $600 \mathrm{~W}$ ultrasonic power and $350 \mathrm{kPa}$ solidification pressure 

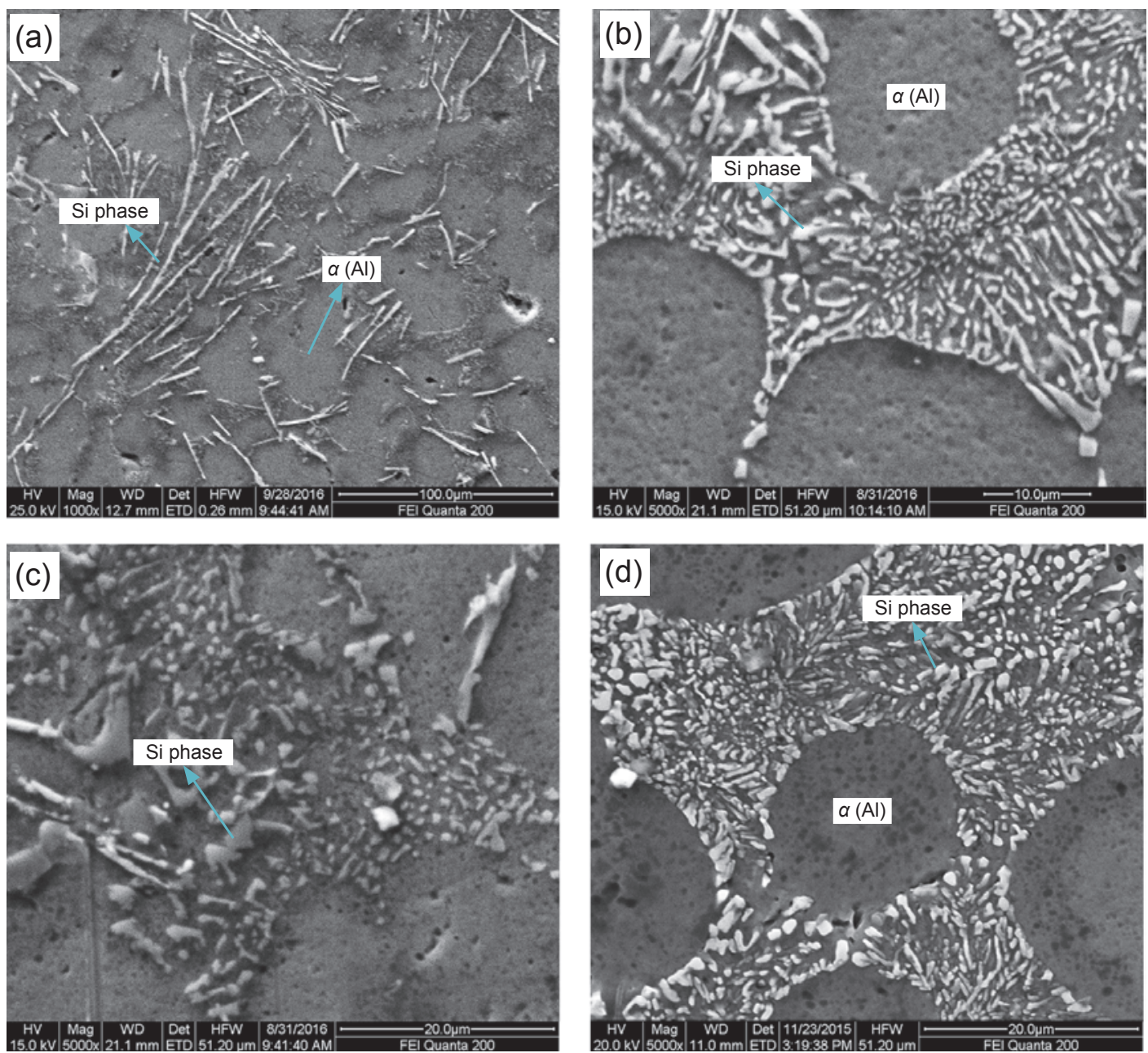

Fig. 9: SEM image of ZL114A alloys under different conditions: (a) Gravity casting; (b) 600 W ultrasonic power; (c) $350 \mathrm{kPa}$ solidification pressure; (d) Synergistic action of $600 \mathrm{~W}$ ultrasonic power and $350 \mathrm{kPa}$ solidification pressure

and shown in Fig. 9. In traditional gravity casting, the eutectic silicon of ZL114A alloy was mainly large strip and integrated clusters, as shown in Fig. 9(a). When the ultrasonic vibration and solidification pressure are applied seperately, the eutectic silicon phases of ZL114A alloy are refined and dispersed, although there are still some strips and bulky eutectic silicon phases, as shown in Fig. 9(b) and (c). Under the synergistic action of ultrasonic vibration and solidification pressure, the strip and massive eutectic silicon are converted completely into the small short rod-like and evenly distributed $\mathrm{Si}$ phases at the grain boundary of primary $\alpha-\mathrm{Al}$, as shown in Fig. $9(\mathrm{~d})$.

Under synergistic action of ultrasonic power and solidification pressure, the molten ZL114A alloy is affected by ultrasonic action and solidification pressure simultaneously. Therefore, the cavitation-extrusion and infiltration effects are produced under the coupled action of ultrasonic vibration cavitation and extrusion and infiltration effect during vacuum counter-pressure casting ${ }^{[20]}$. The sketch map of synergistic action of ultrasonic power and solidification pressure is shown in Fig. 10.

Under the synergistic action of ultrasonic vibration $(U)$ and solidification pressure, the pressure at the location among solidification dendrites is the sum of the solidification pressure by vacuum counter-pressure casting and the acoustic pressure

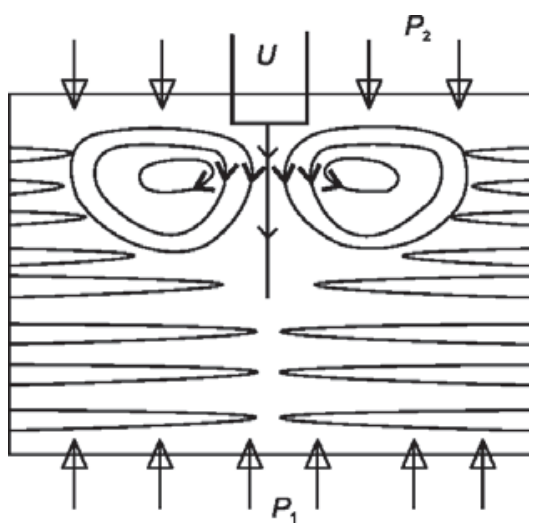

Fig. 10: Schematic graph of synergistic action of ultrasonic vibration and solidification pressure

by ultrasonic vibration, as listed below:

$$
P_{X}=P_{1 X}+P_{2 X}
$$

where $P_{1 X}$ is solidification pressure at $X$ location among dendrites, $\mathrm{Pa} ; P_{2 X}$ is acoustic pressure at $X$ location by ultrasonic vibration, $\mathrm{Pa}$.

During the solidification feeding process of vacuum counterpressure casting, the pressure loss of molten metal at $X$ location 
among dendrites can be expressed as ${ }^{[21]}$ :

$$
\begin{gathered}
P_{X 1}=P_{K}-\frac{8 v \mu X}{\delta^{2}} \\
\Sigma P=P_{K}-P_{1 X}=\frac{8 v \mu X}{\delta^{2}}
\end{gathered}
$$

where $P_{K}$ is solidification pressure, $v$ is flow velocity of molten metal, $\mu$ is dynamical viscosity coefficient, and $\delta$ is the size of feeding channel at $X$ location among dendrites.

The flow velocity of molten metal can be expressed as:

$$
v=\frac{\beta}{1-\beta} R
$$

where $\beta$ is the coefficient of solidification contraction, and $R$ is solidification velocity, $\mathrm{m} \cdot \mathrm{s}^{-1}$.

The solidification pressure at $X$ location among dendrites can be obtained by substituting Eq. (5) into Eq. (4).

$$
P_{1 X}=P_{K}-\frac{8 \beta \mu X}{(1-\beta) \delta^{2}} R
$$

According to the principle of acoustics, there exists attenuation in the propagation of acoustic pressure, and the attenuation of ultrasonic intensity in molten metal can be expressed as:

$$
I_{X}=I_{0} e^{-a_{n} X}
$$

where $I_{X}$ is acoustic intensity at $X$ distance from acoustic source, $\mathrm{N} \cdot \mathrm{mm}^{-2}, I_{0}$ is the ultrasonic intensity, $\mathrm{N} \cdot \mathrm{mm}^{-2}, a_{n}$ is absorption coefficient of molten metal.

The relationship between acoustic intensity and acoustic pressure can be expressed as ${ }^{[22]}$.

$$
I_{X}=P_{2 X}^{2} / \rho c
$$

where $\rho$ is density, $\mathrm{kg} \cdot \mathrm{m}^{-3} ; c$ is acoustic speed, $\mathrm{m} \bullet \mathrm{s}^{-1}$.

The acoustic pressure at $X$ location by ultrasonic vibration can be obtained:

$$
P_{2 X}=\left(I_{0} \rho c\right)^{\frac{1}{2}} e^{-\frac{a_{n}}{2} X}
$$

The cavitation-extrusion and infiltration capacity under synergistic action of ultrasonic vibration and solidification pressure can be obtained by substituting Eq. (2), (6) and (9) into Eq. (1):

$$
\Delta G=\frac{K\left(P_{K}-\frac{8 \beta \mu X}{(1-\beta) \delta^{2}} R+\left(I_{0} \rho c\right)^{\frac{1}{2}} e^{-\frac{a_{n}}{2} X}+\frac{2 \sigma}{r}-P_{s}-P_{g}\right)}{\mu \Delta L} F \cdot \Delta \tau
$$

It can be seen from Eq. (10), the cavitation-extrusion and infiltration capacity is mainly related to solidification pressure and ultrasonic intensity. The cavitation-extrusion and infiltration effect can break up not only the primary phases, which are beneficial to grain refinement and mechanical properties improvement, but also the dendrites, which form continuous skeleton and isolated liquid area during cavitationextrusion and infiltration process. The dendrites will be plastically deformed, even rushed and broken by the molten metal flow when their strength is lower than the feeding pressure among dendrites. This feeding pressure is the sum of the solidification pressure by vacuum counter-pressure casting and the acoustic pressure by ultrasonic vibration. Therefore, the cavitation-extrusion and infiltration effect will result in an increase in the amount of dissociated grains, the refinement of grain and improvement of mechanical properties. Figure 11 shows how the ultrasonic power and solidification pressure affect the density of the alloy. With the increase of ultrasonic power and solidification pressure, the density of ZL114A samples gradually increases, and reaches its peak under synergistic action of $600 \mathrm{~W}$ ultrasonic power and $350 \mathrm{kPa}$ solidification pressure.

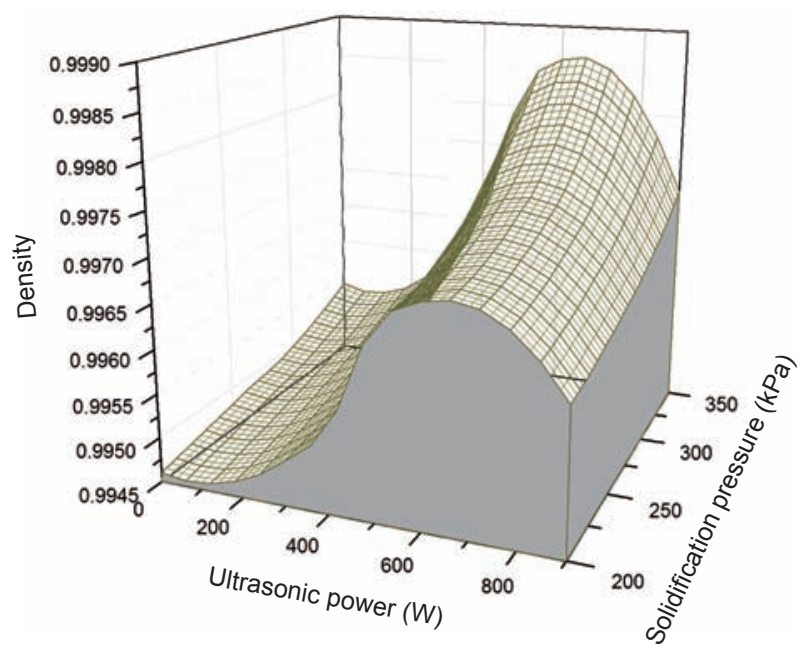

Fig. 11: Dependence of alloy density on ultrasonic power and solidification pressure

\section{Conclusions}

(1) The synergistic action of ultrasonic vibration and solidification pressure can result in grain refinement and tensile property improvement of vacuum counter-pressure casting ZL114A aluminum alloy. Both the tensile strength and elongation of the alloy are the highest under the conditions of $600 \mathrm{~W}$ ultrasonic power and $350 \mathrm{kPa}$ solidification pressure. Moreover, the tensile fracture morphology shows obvious ductile fracture characteristics. When the solidification pressure is less than $300 \mathrm{kPa}$, the effect of ultrasonic power on tensile strength and elongation is obvious, but when the solidification pressure is more than $300 \mathrm{kPa}$, the effect of solidification pressure on tensile strength and elongation is greater.

(2) The size and morphology of the eutectic silicon were optimized significantly by ultrasonic vibration and pressurized solidification. The strip and bulky eutectic silicon phases convert completely into small short rod-like and evenly distributed $\mathrm{Si}$ phases at the grain boundary of primary $\alpha-\mathrm{Al}$. 


\section{References}

[1] Amneelahi M, Shabestari S G. Effect of various melt and heat treatment conditions on impact toughness of A356 aluminum alloy. Transactions of Nonferrous Metals Society of China, 2016, 26: 956-965.

[2] Shin J S, Ko S H, Kim K T. Development and characterization of low-silicon cast aluminum alloys for thermal dissipation. Journal of Alloys and Compounds, 2015, 644(25): 673-686.

[3] Dioni D, Cecchel S, Cornacchia G, et al. Effects of artificial aging conditions on mechanical properties of gravity cast B356 aluminum alloy. Transactions of Nonferrous Metals Society of China, 2015, 25: 1035-1042.

[4] Yan Qingsong, Yu Huan, Wei Bokang, et al. Defects analysis and control of car cylinder head castings of aluminum alloy. Failure Analysis and Prevention, 2009, 4(1): 30-34. (In Chinese)

[5] Ramirez A, Qian M, Davis B. Potency of high-intensity ultrasonic treatment for grain refinement of magnesium alloys. Scripta Materialia, 2008, 59: 19-22.

[6] Atamanenko T V, Eskin D G, Zhang L. Criteria of Grain Refinement Induced by Ultrasonic Melt Treatment of Aluminum Alloys Containing $\mathrm{Zr}$ and $\mathrm{Ti}$. Metallurgical and Materials Transactions A, 2010, 41(8): 2056-2066.

[7] Jiang Ripeng, Li Xiaoqian, Zhang Min. Investigation on the mechanism of grain refinement in aluminum alloy solidified under ultrasonic vibration. Metals and Materials International, 2015, 21(1): 104-108.

[8] Li Yinglong, Li Baomian, Liu Yong tao, et al. Effect of highintensity ultrasonic on structures and properties of Al-Si alloys. The Chinese Journal of Nonferrous Metals, 1999, 9(4): 719722.

[9] Eskin G I. Cavitation mechanism of ultrasonic melt degassing. Ultrasonics Sonochemistry, 1995, 2(2): 137-141.

[10] Eskin G I. Broad prospects for commercial application of the ultrasonic (cavitation) melt treatment of light alloys. Ultrasonics Sonochemistry, 2001, 8(3): 319-325.

[11] Tzanakis I, Lebon G S B, Eskin D G, et al. Investigation of the factors influencing cavitation intensity during the ultrasonic treatment of molten aluminium. Materials \& Design, 2016, 90: 979-983.
[12] Tzanakis I, Xu W W, Eskin D G, et al. In situ observation and analysis of ultrasonic capillary effect in molten aluminium. Ultrasonics Sonochemistry, 2015, 27: 72-80.

[13] Akad A T. Counter-pressure casting: The processes which occur during casting and crystallization. Foundry Trade Journal, 1989, 10: 744-750.

[14] Yan Qingsong, Yu Huan, Lu Gang, et al. Density and solidification feeding model of vacuum counter-pressure cast aluminum alloy under grade-pressuring conditions. China Foundry, 2016, 13(2): 47-52.

[15] Yan Qingsong, Yu Huan, Xu Zhifeng, et al. Effect of holding pressure on the microstructure of vacuum counter-pressure casting aluminum alloy. Journal of Alloys and Compounds, 2010, 501: 352-357.

[16] Eskin G I, Makarov G S. Effect of cavitation melt treatment on the structure refinement and property improvement in cast and deformed hypereutectic Al-Si alloys. Materials Science Forum, 1997, 242: 65-70.

[17] Huang Haijun, Xu Yifan, Shu Da, et al. Effect of ultrasonic melt treatment on structure refinement of solidified high purity aluminum. Transactions of Nonferrous Metals Society of China, 2014, 24(7): 2414-2419.

[18] Yan Qingsong, Yu Huan, Lu Gang, et al. Effect of crystallization pressure on secondary dendrite arm spacing of vacuum counter-pressure casting aluminum alloy. The Chinese Journal of Nonferrous Metals, 2014, 24(5): 1194-1199. (In Chinese)

[19] Kovacheva R, Bachvarov G, Dafinova R. Influence of the Counter Pressure Casting Conditions on the Microstructural Characteristics of AISi7Mg Castings. Journal of Materials Science and Technology, 1996, 12(1): 42-56.

[20] Yan Qingsong, Lu Gang, Li Cheng, et al. Effect of synergistic action between ultrasonic power and solidification pressure on secondary dendrite arm spacing of vacuum counter-pressure casting aluminum alloy. Chinese Journal of Nonferrous Metals, 2017, 27(01): 51-56. (In Chinese)

[21] Kubo K, Pehlke R. Mathematical modeling of porosity formation in solidification. Metallurgical Transactions B, 1985, 16: 359-363.

[22] Ying Chongfu. Ultrasonic. Beijing: Science Press, 1990. (In Chinese)

This research was financially supported by the National Natural Science Foundation of China (No. 51261025) and the Aerospace Science and Technology Innovation Foundation of Shanghai, China (No. SAST2016046) and the Key Projects of Superior Science and Technology Innovation Team of Jiangxi, China (No. 20181BCB19001). 